\title{
Monitoring and projecting cancer incidence in Saarland, Germany, based on age-cohort analyses
}

\author{
Hermann Brenner, Hartwig Ziegler
}

\begin{abstract}
Study objective-The aims were (1) to monitor and compare incidence rates of cancer from successive birth cohorts in Saarland over the period from 1968 to 1987; (2) to project cancer incidence in Saarland in 1988-2002 in order to provide guidelines for health policy planning.

Design-This was an ecological study of overlapping birth cohorts of women and men.
\end{abstract}

Setting-The study was population based involving the whole state of Saarland.

Patients -80028 cases of malignant neoplasms (other than non-melanoma skin cancer) diagnosed from 1968 to 1987 and reported to the cancer registry of Saarland were included.

Measurements and main results-Age specific, sex specific, and period specific cancer incidence rates were analysed and extrapolated by multiplicative age-cohort models. Due to a steady rise in birth cohort specific cancer incidence rates in males, a substantial rise in incidence of total cancer is projected, while a moderate decline is expected for females. Analogous analyses are presented for the most common single forms of cancer in women and men. Alternative strategies of analysis, such as age-period-cohort modelling, are discussed.

Conclusions-The age-cohort model is well suited for monitoring incidence of most forms of cancer. The projections provide quantitative guidelines for planning of health care resources and underline and quantify the challenge for primary and secondary cancer prevention in Saarland.

University of Ulm, Unit of Epidemiology, Am Hochsträss 8, D-7900 Ulm, Germany H Brenner Cancer Registry of Saarland, Saarbrücken, Germany H Ziegler

Correspondence to: Dr Brenner

Accepted for publication February 1991
Surveillance of chronic disease occurrence in populations is most commonly based on monitoring of time trends in age specific and age standardised mortality or (if population based disease registers are available) incidence rates. This also applies to malignant neoplasms although it is usually biologically more plausible that changes in population based cancer rates follow birth cohort rather than calendar period patterns. ${ }^{2}$

Basic descriptive techniques of birth cohort analysis $^{34}$ have been supplemented by various forms of mathematical modelling in the past two decades. Most commonly, cancer incidence or mortality rates have been modelled as a sometimes also period of diagnosis. These agemultiplicative function of age, birth cohort, and period-cohort models are, however, subject to the well known identifiability problem due to the linear dependency between the three predictor variables, unless additional constraints are imposed on the parameter estimates. ${ }^{5-7}$ These additional constraints sensitively affect the estimated parameters. ${ }^{8}$

The purpose of modelling birth cohort specific incidence rates is twofold: first, the indentification of "birth cohort effects" is of major interest in cancer aetiology; second, the estimates can be used to project future incidence rates, which is very relevant in health care planning and the implementation of early detection programmes. However, additional assumptions have to be made in this context, such as the extrapolation of recent trends, ${ }^{9}$ which is always hazardous.

In this paper, a multiplicative age-cohort model is fitted to cancer incidence rates of Saarland, Germany, in order to describe concisely the relative incidence of various birth cohorts and to estimate future cancer incidence rates. Simultaneous estimation of age, period, and birth cohort effects, as well as extrapolation of recent trends in birth cohort effects, is purposely avoided.

\section{Methods}

Within the former Federal Republic of Germany, Saarland is the only state for which reliable cancer incidence rates have been recorded during the last two decades. ${ }^{1011}$ Saarland covers a small highly industrialised area in the south west of Germany. The total population is about 1.05 million persons. The population based cancer registry of Saarland was established in 1966. Our analyses are based on incident cases of malignant neoplasms (ICD-9 positions 140-208) registered in the 20 year period from 1968 to 1987 . However, malignant and semi-malignant (non-melanoma) tumours of the skin (ICD-9 position 173), which are known to be subject to varying degrees of underreporting, ${ }^{11}$ were excluded.

The basic data layout is illustrated in table $I$ : there are 72 cells of observed incidence rates (from 1968 to 1987) which are defined by age (left column) and either period of diagnosis (top row) or alternatively central years of birth of overlapping birth cohorts (numbers within cells). Although incidence rates in the oldest age category truly represent a weighted average of incidence rates in various birth cohorts, they are, for simplification, fully ascribed to the cohorts aged 85 to 90 years in the given calendar periods which contribute the vast majority of personyears and cases in this age group. 
A multiplicative model of the form

$$
\log \mathrm{C}_{\mathrm{ac}}=\mathrm{N}_{\mathrm{ac}}+\alpha_{\mathrm{a}}+\tau_{\mathrm{c}}+\text { error }_{\mathrm{ac}}
$$

was fitted to the data, where age effects are represented by $\alpha_{a}$, "birth cohort effects" by $\tau_{c}$, and person-years and observed numbers of cases for cohorts $\mathrm{c}$ at ages a by $\mathrm{N}_{\mathrm{ac}}$ and $\mathrm{C}_{\mathrm{ac}}$. Personyears are regarded as fixed numbers, and numbers of cases are assumed to arise from independent Poisson distributions. The procedure can be interpreted as a refined form of indirect standardisation of incidence rates, ${ }^{12}$ which estimates "standardised incidence ratios" for successive birth cohorts. For simplification, the terms "cohort standardised incidence ratios" and "cohort effects" are used interchangeably from now on. The statistical modelling was carried out using the software package GLIM. ${ }^{13}$ In order to stabilise the parameter estimates for the youngest birth cohorts, which is crucial for the purpose of prediction, a common cohort parameter was estimated for the cohorts with central years of birth

Table I Principle of age-cohort analysis: age (first column) and central year of birth (figures within the cells) corresponding to observed and projected age specific cancer incidence rates (ICD-9 positions 140-208 except 173)

\begin{tabular}{|c|c|c|c|c|c|c|c|}
\hline \multirow[b]{3}{*}{ Age } & \multicolumn{7}{|c|}{ Calendar period } \\
\hline & \multicolumn{4}{|c|}{ Observed } & \multicolumn{3}{|c|}{ Projected } \\
\hline & $\begin{array}{l}1968- \\
1972\end{array}$ & $\begin{array}{l}1973- \\
1977\end{array}$ & $\begin{array}{l}1978- \\
1982\end{array}$ & $\begin{array}{l}1983- \\
1987\end{array}$ & $\begin{array}{l}1988- \\
1992\end{array}$ & $\begin{array}{l}1993- \\
1997\end{array}$ & $\begin{array}{l}1998- \\
2002\end{array}$ \\
\hline $0-4$ & 1968 & 1973 & young & young & young & young & young \\
\hline $5-9$ & 1963 & 1968 & 1973 & young & young & young & young \\
\hline $10-14$ & 1958 & 1963 & 1968 & 1973 & young & young & young \\
\hline 15-19 & 1953 & 1958 & 1963 & 1968 & 1973 & young & young \\
\hline $20-24$ & 1948 & 1953 & 1958 & 1963 & 1968 & 1973 & young \\
\hline $25-29$ & 1943 & 1948 & 1953 & 1958 & 1963 & 1968 & 1973 \\
\hline $30-34$ & 1938 & 1943 & 1948 & 1953 & 1958 & 1963 & 1968 \\
\hline $35-39$ & 1933 & 1938 & 1943 & 1948 & 1953 & 1958 & 1963 \\
\hline $40-44$ & 1928 & 1933 & 1938 & 1943 & 1948 & 1953 & 1958 \\
\hline $45-49$ & 1923 & 1928 & 1933 & 1938 & 1943 & 1948 & 1953 \\
\hline $50-54$ & 1918 & 1923 & 1928 & 1933 & 1938 & 1943 & 1948 \\
\hline $55-59$ & 1913 & 1918 & 1923 & 1928 & 1933 & 1938 & 1943 \\
\hline $60-64$ & 1908 & 1913 & 1918 & 1923 & 1928 & 1933 & 1938 \\
\hline 65-69 & 1903 & 1908 & 1913 & 1918 & 1923 & 1928 & 1933 \\
\hline $70-74$ & 1898 & 1903 & 1908 & 1913 & 1918 & 1923 & 1928 \\
\hline $75-79$ & 1893 & 1898 & 1903 & 1908 & 1913 & 1918 & 1923 \\
\hline $80-84$ & 1888 & 1893 & 1898 & 1903 & 1908 & 1913 & 1918 \\
\hline$\geqslant 85$ & 1883 & 1888 & 1893 & 1898 & 1903 & 1908 & 1913 \\
\hline
\end{tabular}

Table II Principle of age-cohort analysis starting from age 40 years: age (first column) and central year of birth (figures within the cells) corresponding to observed and projected age specific cancer incidence rates (selected forms of cancer)

\begin{tabular}{|c|c|c|c|c|c|c|c|}
\hline \multirow[b]{3}{*}{ Age } & \multicolumn{7}{|c|}{ Calendar period } \\
\hline & \multicolumn{4}{|c|}{ Observed } & \multicolumn{3}{|c|}{ Projected } \\
\hline & $\begin{array}{l}1968- \\
1972\end{array}$ & $\begin{array}{l}1973- \\
1977\end{array}$ & $\begin{array}{l}1978- \\
1982\end{array}$ & $\begin{array}{l}1983- \\
1987\end{array}$ & $\begin{array}{l}1988- \\
1992\end{array}$ & $\begin{array}{l}1993- \\
1997\end{array}$ & $\begin{array}{l}1998- \\
2002\end{array}$ \\
\hline $40-44$ & 1928 & 1933 & young & young & young & young & young \\
\hline $45-49$ & 1923 & 1928 & 1933 & young & young & young & young \\
\hline $50-54$ & 1918 & 1923 & 1928 & 1933 & young & young & young \\
\hline $55-59$ & 1913 & 1918 & 1923 & 1928 & 1933 & young & young \\
\hline $60-64$ & 1908 & 1913 & 1918 & 1923 & 1928 & 1933 & young \\
\hline $65-69$ & 1903 & 1908 & 1913 & 1918 & 1923 & 1928 & 1933 \\
\hline $70-74$ & 1898 & 1903 & 1908 & 1913 & 1918 & 1923 & 1928 \\
\hline $75-79$ & 1893 & 1898 & 1903 & 1908 & 1913 & 1918 & 1923 \\
\hline $80-84$ & 1888 & 1893 & 1898 & 1903 & 1908 & 1913 & 1918 \\
\hline$\geqslant 85$ & 1883 & 1888 & 1893 & 1898 & 1903 & 1908 & 1913 \\
\hline
\end{tabular}

1978 and 1983. Rather than extrapolating trends in the youngest birth cohorts, the same parameter estimate was also assigned to all subsequent birth cohorts in the prediction of future incidence rates. Cohort effects for all other birth cohorts, as well as age effects, were also assumed to remain constant throughout the projection period. Observed (1968-87) and projected (1988-2002) incidence rates were standardised to the European standard population ${ }^{14}$ by the direct method.

Analogous procedures were applied in the analysis and projection of incidence rates of the most common single forms of cancer starting from suited lower age limits: 30 years for breast and cervical cancer; 40 years for cancer of the stomach, colon, rectum, lung, corpus uteri and ovaries, and 45 years for prostate cancer. Again, in each model, a common cohort effect was estimated for the two youngest birth cohorts under consideration, which was then also applied to subsequent birth cohorts (table II). In addition, cancer incidence rates below the lower age limit were assumed to remain constant from 1983-1987 to 1988-2002 in the projections of future incidence rates (these rates have only minimal impact on overall age standardised incidence rates).

\section{Results}

A rough a priori check of the appropriateness of the multiplicative age-cohort model, which is always advisable, is shown for all forms of cancer (ICD-9 positions 140-208 excluding position 173) in fig 1 . If the multiplicative assumption holds, the age specific incidence rates, displayed by birth cohorts in a semilogarithmic plot, should follow parallel lines, which is approximately true.

Figure 2 shows the estimated cohort effects for all forms of cancer in women and men. The 1918 cohorts were chosen as reference cohorts. The analyses are based on a total of $10 \cdot 3 \star 10^{6}$ personyears and 39159 cases in men and $11 \cdot 4 \star 10^{6}$ person-years and 40869 cases in women.

While standardised incidence ratios were slightly falling for the younger female cohorts beginning with the 1923 birth cohort, a steady and steep increase in relative incidence was observed for male cohorts. The model fit was within an acceptable range for women (deviance $=40 \cdot 1$ at 35 degrees of freedom), but less satisfactory for men (deviance $=77.5$ at 35 degrees of freedom).

Table III shows the age range, total numbers of cases, and person-years included in the models, as well as indicators of the model fit by sex and single forms of cancer. For most of the assessed cancer sites, the model fit (judged by the ratio of the deviance and the degrees of freedom) was good (eg, cervix uteri, corpus uteri) or at least within an acceptable range. However, for prostate cancer, the fit was unsatisfactory.

For stomach cancer, a clear, steady trend toward more favourable rates in younger birth cohorts could be observed in both males and females (fig 3). An opposite trend occurred in colon cancer. No clear patterns were found in the rates of rectal and lung cancer. Breast cancer incidence ratios in women were slowly but almost steadily increasing, while the most impressive reduction of incidence ratios was observed for cancer of the uterine cervix. For endometrial as 


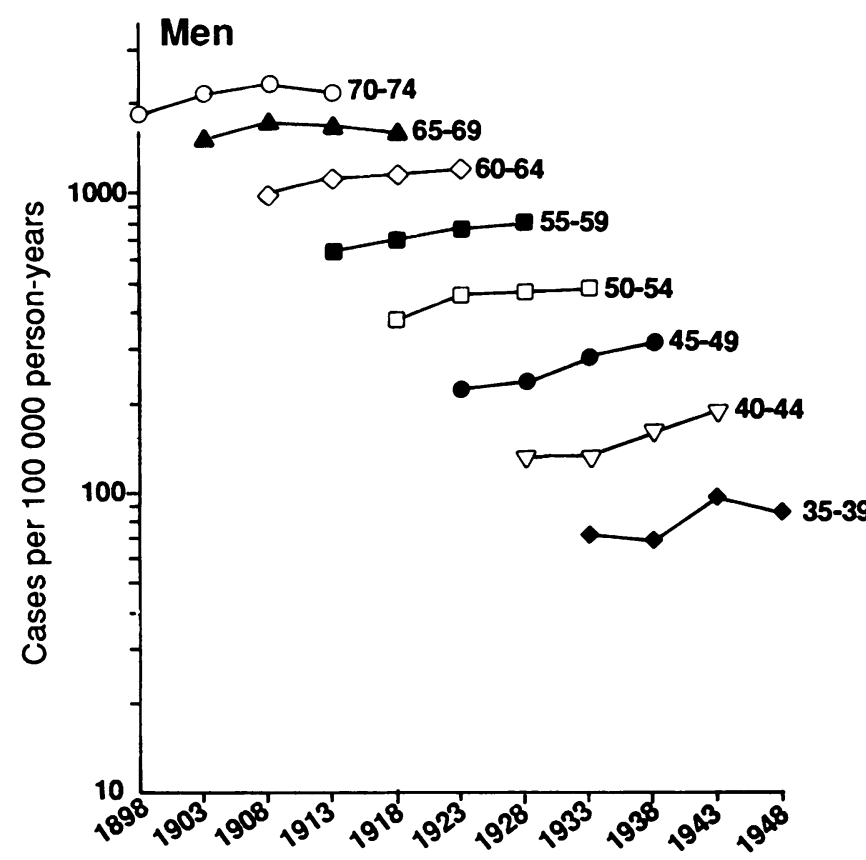

Central year of birth
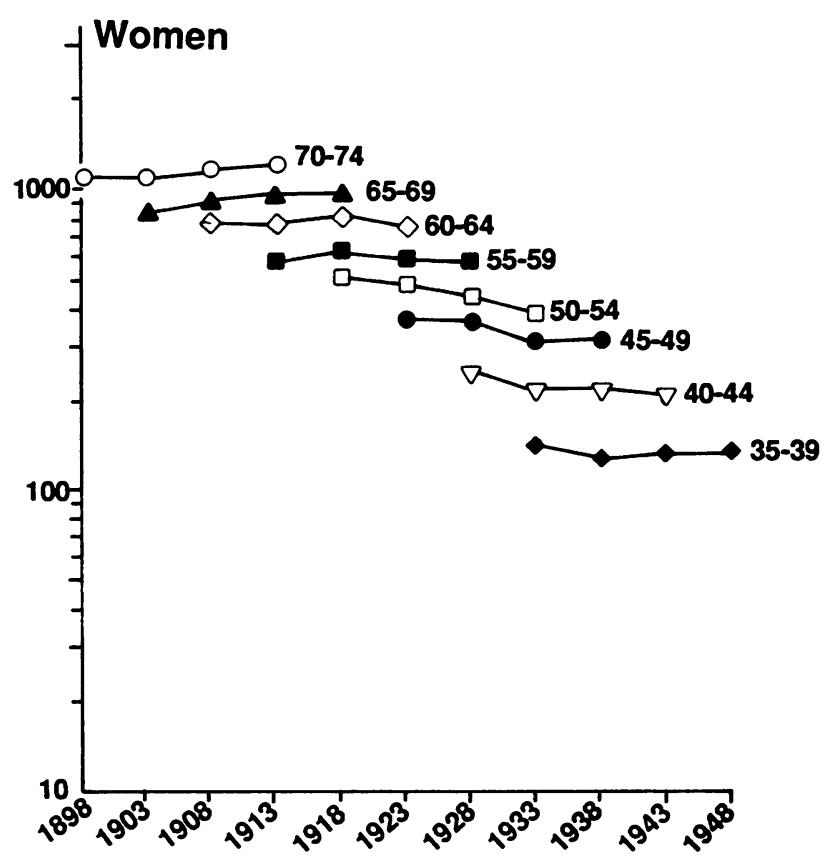

Central year of birth

Figure 1 Age specific incidence rates of all forms of cancer (ICD-9 positions 140-208) excluding non-melanoma skin tumours (ICD-9 position 173) by birth cohorts. Saarland, 1968-1987.

Figure 2 Standardised incidence ratios of all forms of cancer (ICD-9 positions 140-208) excluding non-melanoma position 173) for successive birth cohorts (1918 = reference cohort). Saarland, 1968-1987. skin tumours (ICD-9

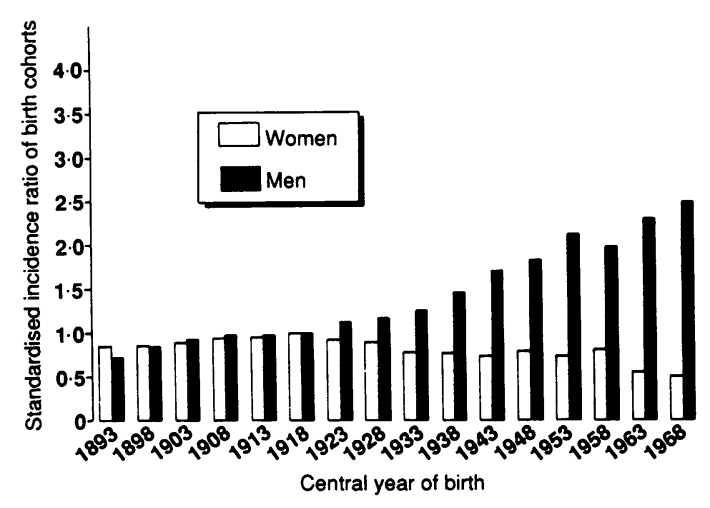

well as ovarian cancer, incidence ratios increased substantially from the 1893 to the 1918 cohort, but fell again in younger birth cohorts. A modest increase in incidence ratios was observed for prostate cancer.

Figure 4 displays observed and projected age standardised incidence rates for all forms of cancer. The rise in incidence rates observed from 1968-1972 to $1983-1987$ in men is expected to continue and even accelerate throughout the projection period, while for women a further decline is projected. The overall change from

Table III Age range, total person-years, total number of cases and indicators of model fit by sex and single forms of cancer

\begin{tabular}{|c|c|c|c|c|c|c|c|}
\hline Site & $I C D-9$ & $\begin{array}{l}\text { Age } \\
\text { range }\end{array}$ & Sex & $\begin{array}{l}\text { Person- } \\
\text { years }\end{array}$ & Cases & $d e v^{a}$ & $d f^{b}$ \\
\hline Stomach & 151 & $\geqslant 40$ & $\begin{array}{l}\mathrm{m} \\
\mathrm{f}\end{array}$ & $\begin{array}{l}4 \cdot 15 * 10^{6} \\
5 \cdot 47 * 10^{6}\end{array}$ & $\begin{array}{l}3652 \\
3092\end{array}$ & $\begin{array}{l}18 \cdot 4 \\
36.2\end{array}$ & $\begin{array}{l}19 \\
19\end{array}$ \\
\hline Colon & 153 & $\geqslant 40$ & $\mathrm{~m}$ & $\begin{array}{l}4 \cdot 15 \star 10^{6} \\
5 \cdot 47 \star 10^{6}\end{array}$ & $\begin{array}{l}2764 \\
3734\end{array}$ & $\begin{array}{l}37 \cdot 4 \\
19 \cdot 4\end{array}$ & $\begin{array}{l}19 \\
19\end{array}$ \\
\hline Rectum & 154 & $\geqslant 40$ & $\underset{f}{m}$ & $\begin{array}{l}4 \cdot 15 * 10^{6} \\
5 \cdot 47 \star 10^{6}\end{array}$ & $\begin{array}{l}2646 \\
2424\end{array}$ & $\begin{array}{l}40 \cdot 0 \\
23 \cdot 2\end{array}$ & $\begin{array}{l}19 \\
19\end{array}$ \\
\hline Lung & 162 & $\geqslant 40$ & $\underset{f}{m}$ & $\begin{array}{l}4 \cdot 15 * 10^{6} \\
5 \cdot 47 \star 10^{6}\end{array}$ & $\begin{array}{l}9996 \\
1308\end{array}$ & $\begin{array}{l}28 \cdot 3 \\
24 \cdot 7\end{array}$ & $\begin{array}{l}19 \\
19\end{array}$ \\
\hline $\begin{array}{l}\text { Breast } \\
\text { Cervix uteri } \\
\text { Corpus uteri } \\
\text { Ovary } \\
\text { Prostate }\end{array}$ & $\begin{array}{l}174 \\
180 \\
182 \\
183 \\
185\end{array}$ & $\begin{array}{l}\geqslant 30 \\
\geqslant 30 \\
\geqslant 40 \\
\geqslant 40 \\
\geqslant 45\end{array}$ & $\begin{array}{l}f \\
f \\
f \\
f \\
m\end{array}$ & $\begin{array}{l}6.91 \star 10^{6} \\
6.91 \star 10^{6} \\
5.47 \star 10^{6} \\
5.47 \star 10^{6} \\
3.41 \star 10^{6}\end{array}$ & $\begin{array}{l}9606 \\
3045 \\
2708 \\
1737 \\
4098\end{array}$ & $\begin{array}{l}33 \cdot 1 \\
20 \cdot 1 \\
15 \cdot 9 \\
20 \cdot 9 \\
82 \cdot 8\end{array}$ & $\begin{array}{l}23 \\
23 \\
19 \\
19 \\
17\end{array}$ \\
\hline
\end{tabular}

$\mathrm{a}_{\mathrm{dev}}=$ deviance; ${ }^{\mathrm{b}} \mathrm{df}=$ degrees of freedom
1983-87 to $1998-2002$ is projected as $+20 \cdot 6^{\circ}{ }_{0}$ for men and $-15 \cdot 2 \%$ for women.

Clear downward trends of age standardised incidence rates are projected for cancer of the stomach, cervix and corpus uteri, and ovary (fig 5). Almost constant rates are expected for rectal cancer, prostate cancer, and lung cancer in men, while lung cancer rates in women are expected to rise. A moderate rise is expected in breast cancer. The most alarming trend, however, is projected for colon cancer, with an increase of almost $50^{\circ}{ }_{0}$ from 1983-87 to 1998-2002 in men and about $15 \%$ in women.

\section{Discussion}

In our analyses, the basic age-cohort approach compared to more complex age-period-cohort modelling was preferred for several reasons.

(1) Many suspected or known aetiological factors in carcinogenesis are more likely to follow birth cohort rather than period patterns. This applies, for example, to reproductive factors, nutrition during adolescence, start of smoking, etc. Calendar period effects would be of greater concern in surveillance of mortality rates, as progress in therapy may reduce case fatality rates at various ages simultaneously. Similar period effects could, however, occur in incidence rates due to changes in diagnostic procedures such as the implementation of screening programmes. Such effects are likely to have little impact on most cancer forms analysed in this study, but should be kept in mind in the interpretation of detection rates of prostate cancer.

(2) The relative risks estimated by the agecohort analyses have a straightforward interpretation in comparing observed incidence rates of various birth cohorts. No such interpretation is possible in more complex ageperiod-cohort models. 

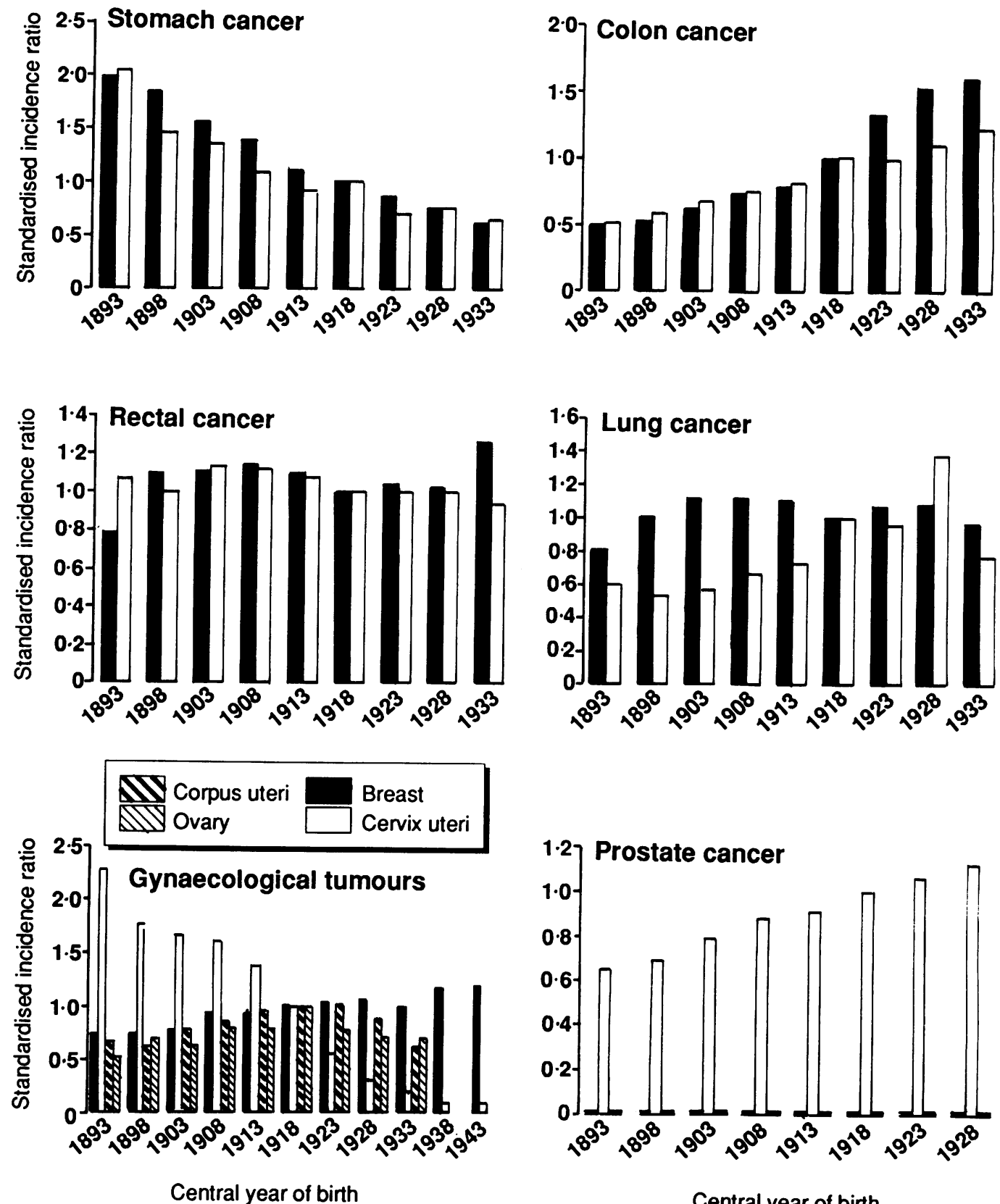

Figure 3 Standardised incidence ratios of the most common single forms of cancer for successive birth cohorts

$(1918=$ reference cohort $)$. Saarland, 1968-1987.

Figure 4 Observed and projected incidence rates of all forms of cancer (ICD-9 positions 140 208) excluding nonmelanoma skin tumours (ICD-9 position 173), directly standardised to the European standard population. Saarland, 1968-2002.

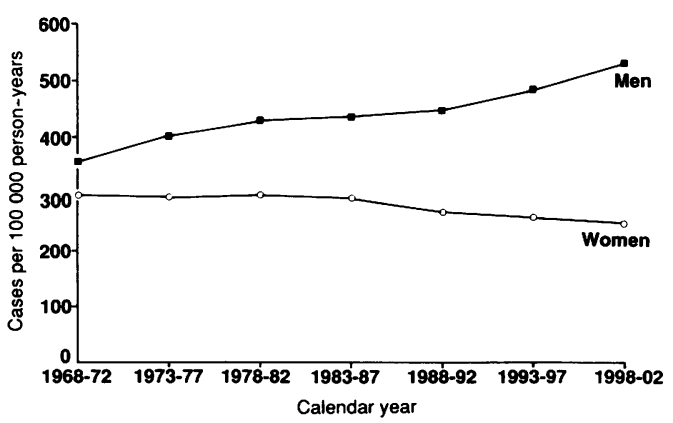

(3) Model building was based on a priori aetiological considerations rather than on the often applied inappropriate formal statistical procedures, which in particular can by no means distinguish between linear cohort or period patterns. $^{8}$

(4) Projections of future cancer incidence rates do not require extrapolation of period effects. They were based on two basic assumptions: (a)

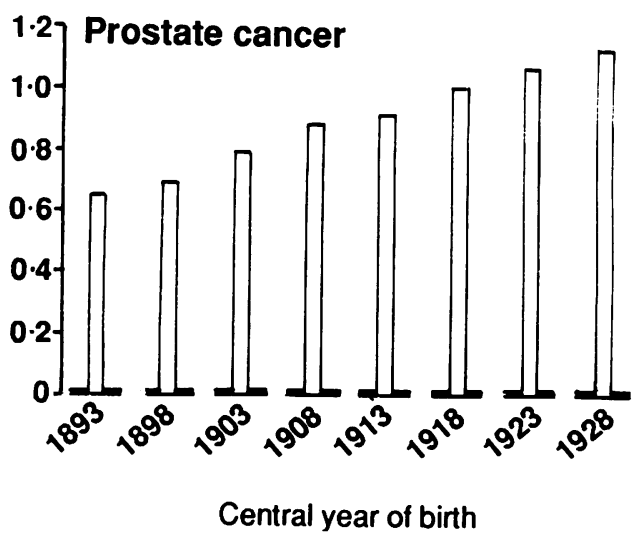

constant age and cohort effects at various calendar periods; (b) a common cohort effect for the youngest birth cohorts. The latter assumption may often not be valid, but the potential error is of little impact in short term projections of overall rates as it applied to young ages where cancer is rare. The same is true for the assumption of constant incidence rates below the lower age limit in the analyses for single forms of cancer.

The model fit, if judged by the ratio of the deviance and the degrees of freedom, was good in most cases but not always fully satisfactory. However, this criterion may be far too stringent and very sensitive to the violation of the Poisson assumption and to sample size. ${ }^{15}$ Alternative criteria have been proposed, such as the proportion of the variance explained by the models, ${ }^{15}$ which would generally suggest a very good model fit. The model fit is, however, clearly unsatisfactory for prostate cancer. As mentioned before, "incidence" of this form of cancer is to a large degree dependent on the extent of screening 
activity, which is likely to follow period rather than cohort patterns. In fact, there was a sharp rise of detection rates of prostate cancer in the 1970 s as a result of intensified diagnostic activity. Results for prostate cancer should therefore be interpreted with caution and are mainly shown for illustrative purposes. Alternative procedures to project prostate cancer "incidence" would be a political rather than a scientific issue, depending on the desired level of prostate cancer detection rates. Interestingly, the model fit was excellent for cervical cancer, although a transient rise in detection rates of preinvasive lesions followed by a sharp decline in incidence rates of invasive cervical cancer in the 1970s might suggest a pronounced period effect of the nationwide screening programme initiated in 1971, which was offered to all age groups above 30 years. ${ }^{16}$ This apparent paradox might be explained by differential use of the programme by various birth cohorts in combination with the long term benefits from screening and early treatment.

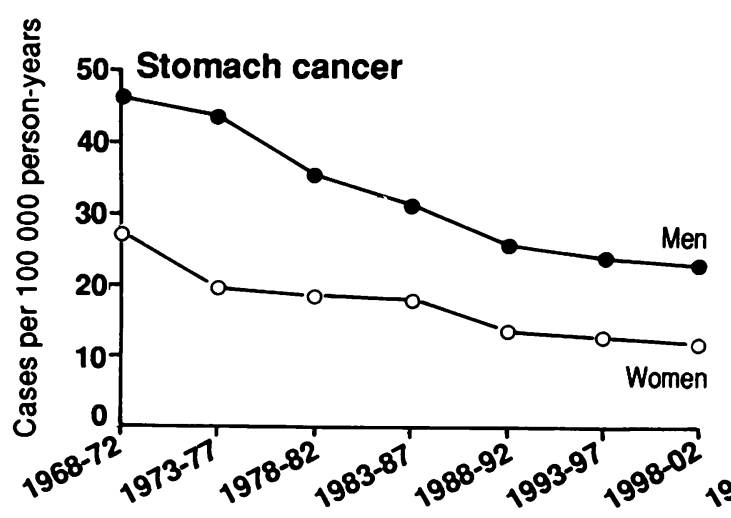

Another important issue is the completeness of registration and changing coding practice over time. In Saarland, the level of completeness is likely to have been rather constant for most cancer sites: overall, the "death certificate only" (DCO) index, an indirect indicator of completeness, was very close to $10 \%$ throughout the period from 1968 to 1987. However, incidence rates of malignant and semi-malignant tumours of the skin other than melanoma (ICD-9 position 173) are notoriously underreported and were therefore excluded. Though not as evident as with prostate cancer, increased sensitivity of diagnosis may explain a minor proportion of the rise in registered rates of colorectal cancer. Finally, changes in classification of cancer of the urinary bladder (which was more often classified as "papilloma" in the past) led to an increase of registration rates of this tumour. These changes may have led to some overestimation of standardised incidence ratios for younger birth cohorts and hence of projected cancer rates.

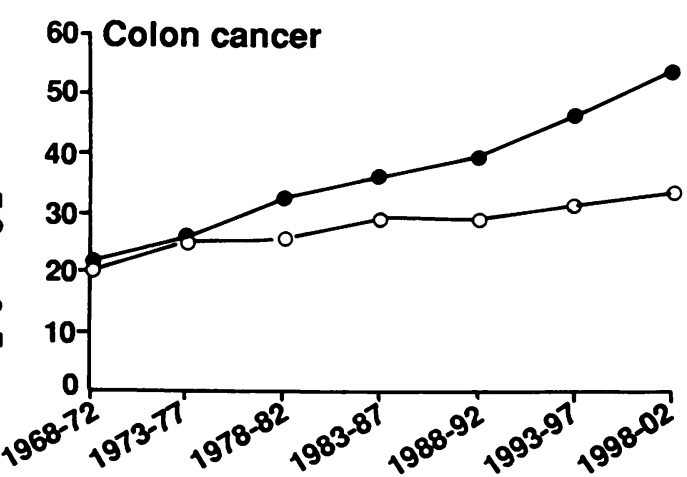

Figure 5 Observed and projected incidence rates of the most common single forms of cancer, directly standardised to the European standard population. Saarland, 1968-2002.
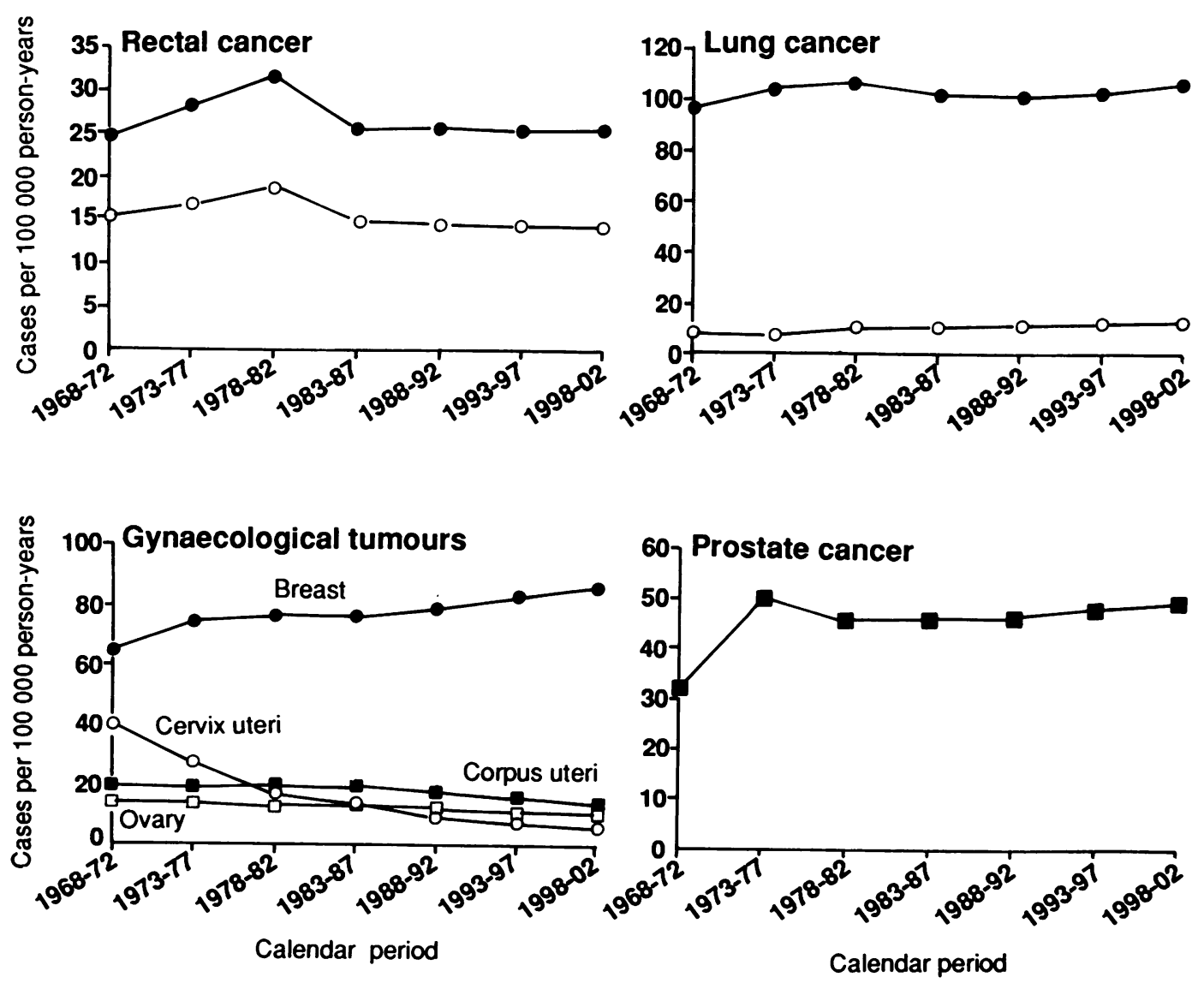
Recent changes in risk factor profiles may modify the projected future cancer incidence rates. As most of the effects of such changes cannot be quantified with satisfactory accuracy due to lack of sufficiently detailed data on risk factor prevalence, we decided to address them in a solely qualitative manner here. For example, the sex differences in lung cancer incidence may diminish more rapidly due to changes in smoking behaviour. Similarly, the increase in breast cancer incidence may be further accelerated by the trend toward delayed childbearing in younger birth cohorts. ${ }^{17}$ Given the continuing rise of breast cancer mortality in Germany ${ }^{18}$ this stresses the need for implementation of a more effective breast cancer screening programme.

The increase in incidence rates of young male cohorts and the observed and projected rise of overall incidence in men are particularly alarming. While for women a substantial reduction in cervical cancer, most likely a result of population-wide screening, ${ }^{16}$ could be observed, no comparable success has so far been achieved for any form of cancer in men. Furthermore, an additional rise in numbers of cancer cases in men has to be expected from the rapid demographic changes currently under way in Germany. ${ }^{19}$

The analyses presented in this paper may serve as guidelines for health politicians in the planning of health care resources. Equally important, they underline and quantify the challenge for primary and secondary cancer prevention. While these most important and promising approaches to cancer control are in need of greater emphasis within most medical care systems worldwide, this does particularly apply to Germany, where epidemiological research and the evaluation of screening programmes continue to be hampered by overly restrictive data protection rules.

One important concern for the purpose of health care planning is whether or not it is possible to make reliable projections of cancer incidence. ${ }^{20}$ The authors will, however, be most pleased if their projections are invalidated by substantial progress in primary prevention.

1 MacMahon B, Terry WD. Application of cohort analysis to the study of time trends in neoplastic disease. $\mathcal{F}$ Chronic Dis 1958; 7: 24-35.

2 Roush GC, Schymura MJ, Holford TR, White C, Flannery JT. Time period compared to birth cohort in Connecticut incidence rates for twenty-five malignant neoplasms. F Natl Cancer Inst 1985; 74: 779-88.

3 Case RAM. Cohort analysis of mortality rates as an historical or narrative technique. Br F Prev Soc Med 1956; 10: 159-71

4 Case RAM. Cohort analysis of cancer mortality in England and Wales, 1911-1954 by site and sex. Br F Prev Soc Med 1956; 10: 172-99.

5 Osmond C, Gardner MJ. Age, period and cohort models applied to cancer mortality rates. Stat Med 1982;1:245-59.

6 Holford TR. The estimation of age, period and cohort effects for vital rates. Biometrics 1983; 39: 311-24.

7 Osmond C, Gardner MJ. Age, period and cohort models: non-overlapping cohorts don't resolve the identification problem. Am f Epidemiol 1989; 129: 31-5.

8 Kupper LL, Janis JM, Karmous A, Greenberg BG. Statistical age-period-cohort analysis: a review and critique. $\mathcal{F}$ Chron Dis 1985; 38: 811-30.

9 Osmond C. Using age, period and cohort models to estimate future mortality rates. Int $\mathcal{\exists}$ Epidemiol 1985; 14: 124-9.

10 Hoffmeister H, ed. Bevölkerungsbezogene Krebsregister in der Hoffmeister H, ed. Bevölkerungsbezogene Krebsregister in der
Bundesrepublik Deutschland. München: MMV Medizin Bundesrepubli

11 Muir CS, Waterhouse J, Mack T, Powell J, Whelan S, eds Cancer incidence in five continents, vol 5. Lyon International Agency for Research on Cancer, 1987.

12 Breslow NE, Day NE. Indirect standardization and multiplicative models for rates, with references to the age adjustment of cancer incidence and relative frequency data. f Chron Dis 1975; 28: 289-303.

13 Payne CD, ed. The GLIM systems release 3.77. Generalized linear interactive modelling manual. Oxford: Numerical Algorithms Group, 1986.

14 Waterhouse J, Muir CS, Correa P, Powell P. Cancer incidence in five continents, vol 3. Lyon: International Agency for Research on Cancer, 1976.

15 Stevens RG, Moolgavkar SH, Lee JAH. Temporal trends in breast cancer. Am f Epidemiol 1982; 115: 759-77.

16 Brenner $\mathrm{H}$, Wiebelt $\mathrm{H}$, Ziegler $\mathrm{H}$. Fortschritte in der Früherkennung des Zervixkarzinoms aus der Sicht des Saarländischen Krebsregisters. Geburtsh u Frauenheilk 1990; 50: 304-9.

17 Brenner H, Stegmaier C. Projected impact of the trend toward delayed childbearing on future breast cancer incidence in the Saarland/W-Germany. Soz Praeventivmed 1990, 35: 1-4.

18 Becker N, Smith EM, Wahrendorf J. Time trends of cancer mortality in the Federal Republic of Germany: progress mortality in the Federal Republic of German

19 Brenner H, Ziegler H. Modellrechnungen zum Einfluß der Brenner $\mathrm{H}$, Ziegler $\mathrm{H}$. Modellrechnungen zum Einfluß der demographischen Entwicklung auf die Krebsinziden
Saarland. Oeff Gesundheitswesen 1989; 51: 743-8.

20 Hakulinen T, Teppo L, Saxén E. Do the predictions for Hakulinen T, Teppo L, Saxén E. Do the predictions for
cancer incidence come true? Experience from Finland. cancer incidence come
Cancer 1986; 57: 2454-8. 